\title{
Distributed Generation system Power Enhancement by per phase Converter and Differential Evolutionary Optimization Controller
}

\author{
Pawan Kumar Tiwari \\ M. Tech Scholar \\ NRI Institute of Research \& Technology \\ Bhopal, India \\ pawantiwari1988@gmail.com
}

\author{
Mrs. Madhu Upadhyay \\ Head of Department \\ NRI Institute of Research \& Technology \\ Bhopal, India \\ madyant44@gmail.com
}

\begin{abstract}
Worldwide renewable energy resources, especially solar energy, are growing dramatically in view of energy shortage and environmental concerns. The main objective of this study the design of a solar photovoltaic system in MATLAB/SIMULINK environment so as to enhance its output capacity before its integration with the grid. And to stabilize and improve the active power output from the solar system by designing an efficient controller for the inverter for DC to AC conversion based on AI optimization technique. Enhance the system reliability and efficiency by integrating it with the grid via a transformer with the desired grid voltage and frequency and studying its performance at different loads.

This work provides a comprehensive design and implementation of power regulatory per phase inverter with proposed differential evolutionary pulse regulation control. Finally the work is made efficiently integrating it with the grid. The designed system is also capable of feeding reactive power to the grid when required. The computational methodology of the proposed modulation technique is very easy and the technique can be applied to the multilevel inverter with any number of levels.

Keywords: PV, inverter, grid, DC, AC.
\end{abstract}

\section{INTRODUCTION}

Worldwide renewable energy resources, especially solar energy, are growing dramatically in view of energy shortage and environmental concerns. Large-scale solar photovoltaic (PV) systems are typically connected to medium voltage distribution grids, where power converters are required to convert solar energy into electricity in such a grid-interactive PV system. To achieve direct medium-voltage grid access without using bulky medium-voltage transformer, cascaded multilevel converters are attracting more and more attraction due to their unique advantages such as enhanced energy harvesting capability implemented by distributed maximum power point tracking (MPPT), improved energy efficiency, lower cost, higher power density, scalability and modularity, Plug-N-power operation, etc.
Motivations are toward addressing the aforementioned issues and approaching to mitigate the negative effect of active power mismatch. MPPT is achieved for each module in these approaches to enhance energy harvesting. However, only unity power factor control was considered and the inherent reactive power compensation capability of the cascaded PV system is ignored. It is recognized that reactive power compensation is able to provide strong voltage support in a wide range. Proper reactive power compensation can significantly improve the system reliability, and in the meantime help the MPPT implementation for the cascaded module under unsymmetrical condition as well as comply with the system voltage requirement simultaneously. All of these have spurred growing interest in reactive power compensation for the cascaded PV system.

\section{LITERATURE REVIEW}

Liming Liu et al. [1] This paper addresses these issues, explores the effects of reactive power compensation and optimization on system reliability and power quality, and proposes coordinated active and reactive power distribution to mitigate this issue. A vector method is firstly developed to illustrate the principle of power distribution.

Tetali Swathi et al. [2] in this paper presented are the renewable energy sources are becoming more popular with ever increasing energy demand and environmental pollution due to non-renewable energy sources. Among the renewable energy sources, major portion of energy is generated using Photovoltaic system. Grid connected photovoltaic systems are gaining more importance.

Hee-Jun Kim et al. [3] This document describes the design of a voltage-based MPPT (Maximum Power Point Tracking) device for photovoltaic (PV) applications. Among the different MPPT methods, the constraint-based method is considered the simplest and most convenient. The main disadvantage of this 
method is that the photovoltaic generator is disconnected from the load to detect its open circuit voltage, which inevitably leads to a loss of power.

Seyed mahmoudian al. [4] the required power of the photovoltaic system (PV) is obtained by combining the photovoltaic modules in the combination of series and parallel arrangements, according to the specifications of the inverter. In general, the conversion in one phase is achieved through the serial connection of the modules to create a voltage higher than the mains voltage.

\section{OBJECTIVE}

There are following objective are to be expected from the present work

- To design a solar photovoltaic system in MATLAB/SIMULINK environment so as to enhance its output capacity before its integration with the grid.

- To provide variable radiation and variable temperature input to each solar module and study its effect on the power output from the system. The work should extract maximum power in these varying input conditions from the solar system.

- To stabilize and improve the active power output from the solar system by designing an efficient controller for the inverter for $\mathrm{DC}$ to $\mathrm{AC}$ conversion based on $\mathrm{AI}$ optimization technique.

- Enhance the system reliability and efficiency by integrating it with the grid via a transformer with the desired grid voltage and frequency and studying its performance at different loads.

\section{Methodology}

The model has been developed in MALAB/SIMULINK environment. It is a matrix / matrix matrix language with control flow instructions, functions, data structures, inputs / outputs and object-oriented programming functions. It has the following main features:

- High level language for scientific and technical computer science

- Desktop environment for exploring, designing and solving iterative problems

- Graphs to display data and tools to create customized graphs

- Applications for curve adaptation, data classification, signal analysis, control optimization and many other tasks

- Complementary toolboxes for various technical and scientific applications

- Tools to create custom applications for the user interface

- Distribution options at no cost for sharing MATLAB programs with end users

The power produced by a single module is seldom enough for commercial use, so modules are connected to form array to supply the load. The connection of the modules in an array is same as that of cells in a module. Modules can also be connected in series to get an increased voltage or in parallel to get an increased current.

The voltage and current available at the terminals of a PV device may directly feed small loads such as lighting systems and DC motors. More sophisticated applications require electronic converters to process the electricity from the PV device. These converters may be used to regulate the voltage and current at the load, to control the power flow in grid connected systems.

The proposed large scale cascaded PV system in which gives the three phase large scale Cascaded PV system in which two stages of power conversion takes place. In 1st stage power harvested from solar panel is given to DC-DC converter for Boost or Buck action i.e for voltage stabilization we are using Current Fed Dual Active Bridge DC-DC converters. The modification is done with cascaded Modular Multilevel Inverters with High Voltage Insulation. DC to DC buck boost control of DC output from the system instead of designing a whole new and separate control algorithm for inverter. In this configuration no need of line frequency transformers, Inverter module is directly connected to grid without any line Frequency Transformers. This is the one of the main advantage of this model compared to conventional methods.

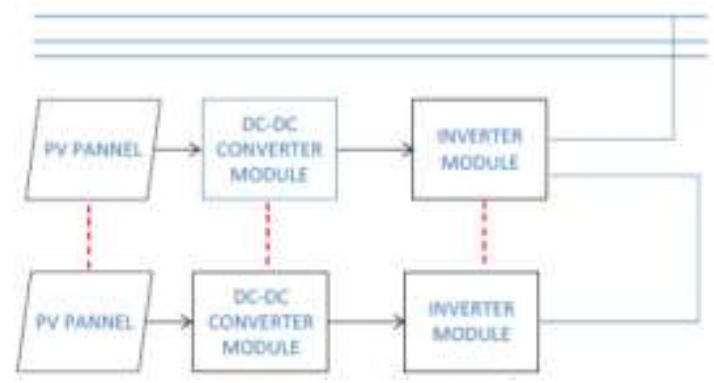

Fig. 1 Proposed control scheme for the modular modeling of per phase inverter

\section{A. PV Module modeling}

An ideal Solar cell is modeled by a current source in parallel with a diode in case of double exponential model i.e. Mono crystalline PV cell. The output current of PV cell depends photon current that can be also determined by load current depending upon the solar insolation during its operation equation.

PV cells have single operating point where the values of the current (I) and voltage (V) of the cell result in a maximum power output. These values correspond to a particular resistance, which is equal to $\mathrm{V} / \mathrm{I}$. 


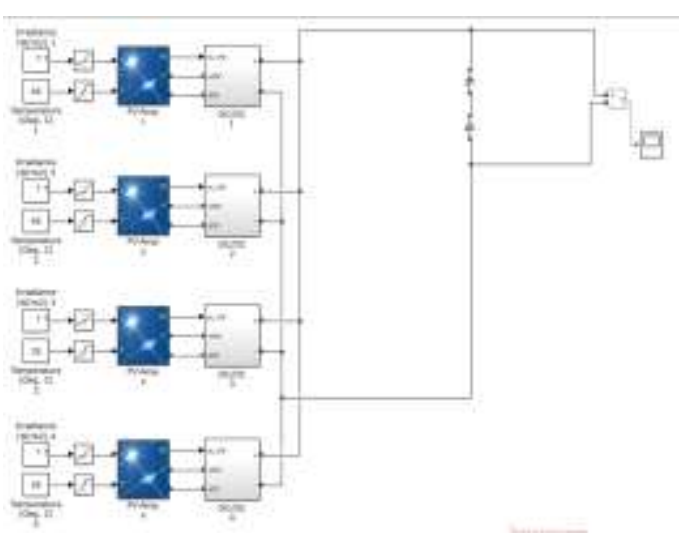

Fig. 2 Modeled solar system

\begin{tabular}{|l|l|l|}
\hline \multicolumn{3}{|l|}{ Table 1 Parameters for solar PV system module } \\
\hline S. No. & System Parameters & Values \\
\hline 1 & Maximum PV power & $315.072 \mathrm{~W}$ \\
\hline 2 & Maximum power point voltage & $54.7 \mathrm{~V}$ \\
\hline 3 & Maximum power point current & $5.76 \mathrm{~A}$ \\
\hline 4 & Open circuit voltage & $64.6 \mathrm{~V}$ \\
\hline 5 & Short-circuit current & $6.14 \mathrm{~A}$ \\
\hline 6 & Nominal utility frequency & $50 \mathrm{~Hz}$ \\
\hline 7 & DC-bus capacitor & $100 \mu \mathrm{F}$ \\
\hline 10 & modules in parallel & 64 \\
\hline 11 & modules in series & 5 \\
\hline
\end{tabular}

A cell series resistance ( Rs ) is connected in series with parallel combination of cellphotocurrent $\mathrm{I}_{\mathrm{ph}}$ ), exponential diode ( D ), and shunt resistance $\left(\mathrm{R}_{\mathrm{sh}}\right)$, I pv and $\mathrm{Vpv}$ are the cells current and voltage respectively. It can be expressed as

$I_{p v}=I_{p h}-I_{s}\left(e^{q\left(V_{p v}+I_{p v} * R_{s}\right) / n K T}-1\right)-\left(V_{p v}+I_{p v}\right.$

Where:

$$
\left.* R_{s}\right) / R_{s h}
$$

$I_{p h}$-Solar-induced current

$I_{S}$ - Diode saturation current

$q$ - Electron charge $\left(1.6 \mathrm{e}^{-19} \mathrm{C}\right)$

$K$ - Boltzmann constant $\left(1.38 \mathrm{e}^{-23} \mathrm{~J} / \mathrm{K}\right)$

$n$ - Ideality factor (1 2)

$T$ - Temperature ${ }^{0} \mathrm{~K}$

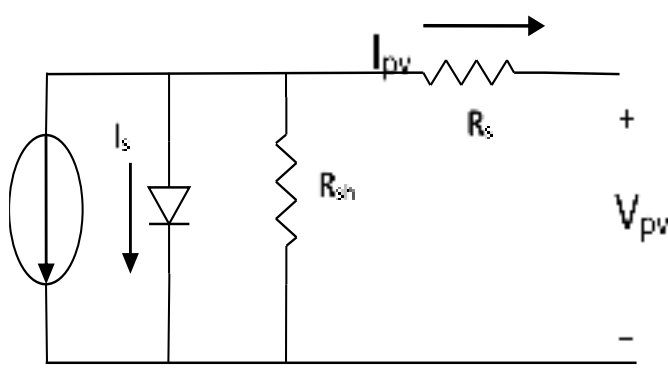

Fig. 3 Equivalent circuit of solar pv cell

The solar induced current of the solar PV cell depends on the solar irradiation level and the working temperature can be expressed as:

$I_{p h}=I_{s c}-k_{i}\left(T_{c}-T_{r}\right) * \frac{I_{r}}{1000}$

Where:

$I_{S C}$ Short-circuit current of cell at STC

$K_{i}$ Cell short-circuit current/temperature coefficient (A/K)

$I_{r}$ Irradiance in $\mathrm{w} / \mathrm{m}$

$T_{C}, T_{r}$ Cell working and reference temperature at STC

A PV cell has an exponential relationship between current and voltage and the maximum power point (MPP) occur at the knee of the curve as shown in the Fig 4.

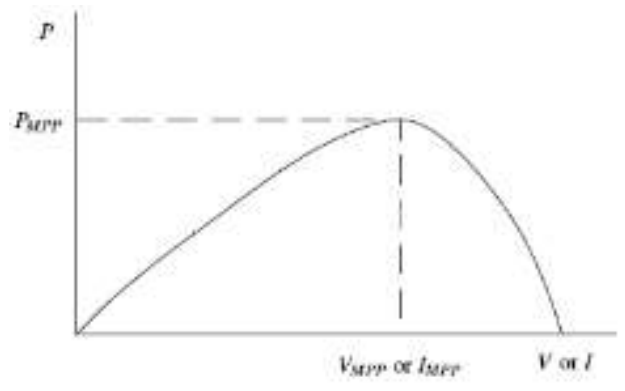

Fig. 4 Characteristic PV array power curve

The $\mathrm{P} \& \mathrm{O}$ algorithm will track the maximum power to supply the DCMGs system. The assumptions for model derivation are that the ideal current source can be presented as the PVs behavior. In addition, all power converters are operated under the continuous conduction mode (CCM) and the harmonics are also ignored.

\section{B. Multi Modular Cell Modeling Control}

The PV farm base distributed generation system consists of four PV arrays at variable irradiation and variable temperature which is considered during modeling. Many factors influence PV cell temperature: module materials and construction, mounting and racking configurations, the incident irradiance (modified by shading and soiling), the wind speed at the array level, and ambient temperature, among other variables. The temperature is kept to be varying for different modules from 35 to 45 . Also irradiation is reduced at 0.5 seconds while the simulation takes place for 1 second. It is developed as a prototype for the distributed generations at various nearby locations whose output is first combined and then integrated with the grid, and hence reducing the equipment necessities.

A single PV array block consist of 64 parallel strings where each string has 5 SunPower SPR-315E modules connected in series.

Each PV array is connected to a DC/DC converter (averaging) before finally providing a common DC input voltage for the inverter. Each boost is controlled by individual Maximum Power Point Trackers (MPPT). The MPPTs use the "Perturb and Observe" technique to vary the voltage across the 
terminals of the PV array in order get the maximum possible power. The final combination of DC output voltages from each string is taken as input DC voltage for inverter

Here in this end we design a buck boost converter control inverter for each phase which can be further integrated with the grid system.

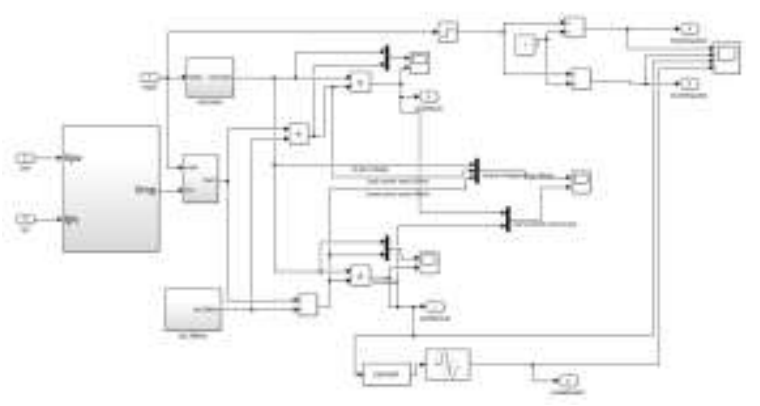

Fig. 5 Combine pulse generation for per phase inverter with buck boost control in MATLAB/SIMULINK

This control is optimized by using differential evolutionary technique. The technique utilizes the power at the load line as optimizing equation for balancing its quality and adjusting according to the load changes. The flow chart of the optimization algorithm has been shown in figure below which is implemented in the MATLAB as governing equations and codes for generating pulses for per phase converter as well as the boosting pulses.

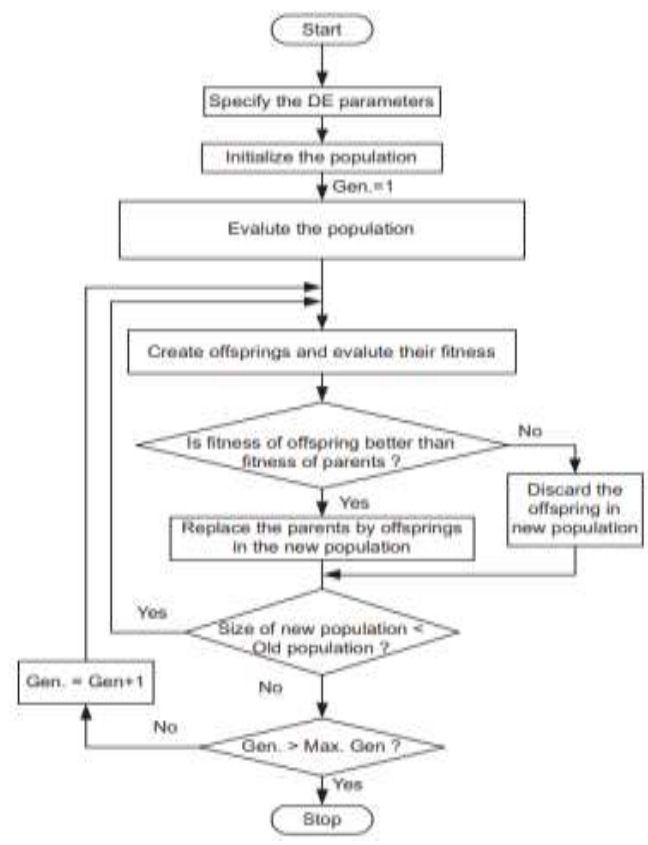

Fig. 6 Flow chart of proposed Differential Evolutionary Algorithm for converters

Differential Evolution (DE) is a population-based heuristic algorithm to solve global optimization problems with different characteristics over continuous space. Despite its simplicity, it proved a great performance in solving non-differentiable, non- continuous and multi-modal optimization problems. In simple DE, DE/rand/1/bin, an initial population of NP individuals $\vec{X}_{J}$ $, \mathrm{j}=1,2, . ., \mathrm{NP}$, is generated at random according to a $\rho$ uniform distribution within lower and upper boundaries $\left(x_{j}^{L}, x_{j}^{U}\right)$. Individuals are evolved by the means of crossover and mutation to generate a trial vector. The trial vector competes with his parent in order to select the fittest to the next generation. The steps of DE are:

\section{Initialization of a population}

Initial population in $\mathrm{DE}$, as the starting point for the process of optimization, is created by assigning a random chosen value for each decision variable in every vector, as indicated in equation:

$$
x_{i j}^{0}=L_{j}+\operatorname{rand}_{j} *\left(U_{j}-L_{j}\right)
$$

Where $, L_{j}, U_{j}$, arethe lower and upper boundaries for $x_{i j}$ rand $_{j}$ random number uniform $[0,1]$.

\section{Mutation}

A mutant vector $V_{i}^{G+1}$ is generated for each target vector $x_{i}^{G}$ at generation $\mathrm{G}$ according to equation (2)

$$
v_{i}^{G+1}=x_{r_{1}}^{G}+F *\left(x_{r_{2}}^{G}-x_{r_{3}}^{G}\right), r_{1} \neq r_{2} \neq r_{3} \neq i
$$

Where $\mathrm{r}_{1}, \mathrm{r}_{2}, \mathrm{r}_{3}$ are randomly chosen from the population. The mutation factor $F \in[0,2]$. A new value for the component of mutant vector is generated using (1) if it violates the boundary constraints.

\section{Recombination (crossover)}

Crossover is the process of swapping information between the target and the mutated individuals using (3), to yield the trial vector $u_{i}^{G+1}$

$$
u_{i j}^{G+1}=\left\{\begin{array}{c}
v_{i j}^{G+1}, \operatorname{rand}(j) \leq C R \text { or } j=\operatorname{rand}(i), \\
x_{i j}^{G}, \operatorname{rand}(j)>C R \text { and } j \neq \operatorname{rand}(i),
\end{array}\right.
$$

A three-phase coupling transformer is used to connect the converter to the grid. The grid model consists of typical $10-\mathrm{kV}$ distribution feeders and equivalent transmission system.

In the average model the boost and VSC converters are represented by equivalent voltage sources generating the $\mathrm{AC}$ voltage averaged over one cycle of the switching frequency. Such a model does not represent harmonics, but the dynamics resulting from proposed control system and power system interaction is preserved. 


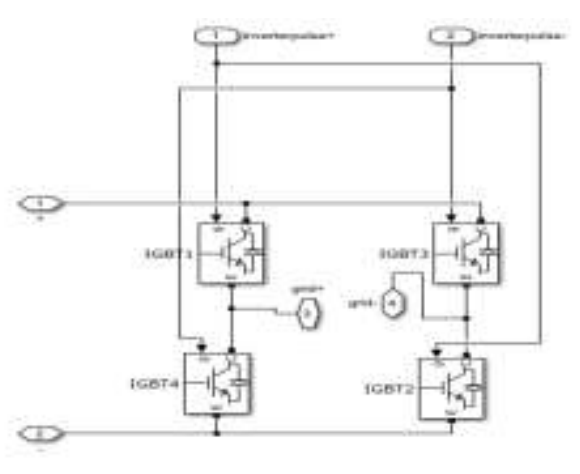

Fig. 7 Per phase inverter modeling

This model allows using much larger time steps (50 us), resulting in a much faster simulation.

\section{LOAD Analysis}

For stability study, to analyze the stability of a system including a power converter and constant power loads. We need to analyze the system stability from the ac side [6], . The method considers a stability study for an ac and dc distribution system connected together via a power converter

Power systems deliver energy to loads that perform a function. These loads range from household appliances to industrial machinery. Most loads expect a certain voltage and, for alternating current devices, a certain frequency and number of phases.

The analysis was carried out for three different industrial loads. The presented results confirm the effectiveness of the proposed approach, which could be assumed as a very useful tool in the design and analysis of a power generation system. The MATLAB simulation has been used in order to obtain the optimum configuration and the sizes of the system components.

Table 2 Shows the parameters considered for the unbalanced load. Unbalanced load makes the lines / phases to carry different current magnitudes, and sum total of these at neutral point is not zero. Load in each phase is different, carrying its own current. Neutral in this case carries the net unbalanced current. For our analysis we have considered resistive load of different magnitude for each phase.

\begin{tabular}{|l|l|}
\hline \multicolumn{2}{|c|}{ Table 2 : Parameters of unbalanced load } \\
\hline Resistive load of phase one (MW) & 0.1 \\
\hline Resistive load of phase two (MW) & 0.2 \\
\hline Resistive load of phase three (MW) & 0.3 \\
\hline
\end{tabular}

Table 3 Shows the parameters considered in our simulation for balanced load. Balanced load in 3 phase system is a condition where all three phases (lines) carry same magnitude of current, with evenly spaced phase difference. The designed power quality enhancement device is made to draw a balanced load having 0.47 MW load for each phase in line.

\begin{tabular}{|l|l|}
\hline \multicolumn{2}{|l|}{ Table 3 : Parameters of balanced load } \\
\hline Resistive load of phase one (MW) & 0.47 \\
\hline Resistive load of phase two (MW) & 0.47 \\
\hline Resistive load of phase three (MW) & 0.47 \\
\hline
\end{tabular}

The parameters and type of loads used during the simulation are being depicted in the figures above. The mixed load analysis help us to make sure that the system is being modeled efficiently for various loading conditions. The use of proposed controller in driving these loads is tested.

\section{Results}

MATLAB stands for MATrix LABoratory, which is a programming package exclusively designed for speedy and effortless logical calculations and Input/output. It has factually hundreds of inbuilt functions for a large form of computations and plenty of toolboxes designed for specific analysis disciplines, as well as statistics, optimization, solution of partial differential equations, information analysis.

In this research work MATLAB platform is used to show the implementation or simulation of implemented algorithm performance

Solar energy is the cleanest and most available renewable energy source. The Modern technology can harness this energy for a variety of uses, including producing electricity, providing light and heating water for domestic, commercial or industrial application. At present, photovoltaic (PV) systems are taking a leading role as a solar-based renewable energy source (RES) because of their unique advantages. This trend is being increased especially in grid-connected applications because of the many benefits of using RESs in distributed generation (DG) systems. Large-scale solar photovoltaic (PV) systems are typically connected to medium-voltage distribution grids, where power converters are required to convert solar energy into electricity in such a grid-interactive PV system

Thus it is important to not only identify the characteristics curves of PV modules or arrays, but also the dynamic behavior of the electronic power converter system (PCS) for connecting to the utility grid. Controlling pulses for theses converters/inverters can vary the output current waveform and thus the active power output from the system. The waveform and pulse provided also depends on the different types of loading conditions at the high voltage line.

The work here is containing solar panels based distributed generations at in an array model in which each DG is expected to receive variable irradiation and varying temperature due to its variation in location. The work here is done in order to not only enhance the power output generated from the renewable energy resource but also to accommodate the variation in temperature and irradiation of the DGs. The proposed converter is expected to accommodate for power variations, 
both active as well as reactive power as according to load changes in the high voltage line. The work is obtained by designing of a multilevel per phase converter technology by utilizing an optimization algorithm that will produce an enhanced and stable output power to the grid.

This chapter shall discuss the output obtained from the solar based renewable energy system that is also meant to be integrated to the grid. The comparative analysis has been carried out in terms of the power output from the system and its quality analysis in terms of total harmonic distortion (THD) at the starting of the system when the power starts rising. The chapter here discusses the outputs in following three cases:

I. CASE 1: DG with multilevel converter per phase having variable irradiation and basic regulatory PWM control

II. CASE 2: Proposed DG system having power regulatory per phase inverter with proposed differential evolutionary PI pulse regulation.

III. Outputs at various loading conditions

IV. VALIDATION

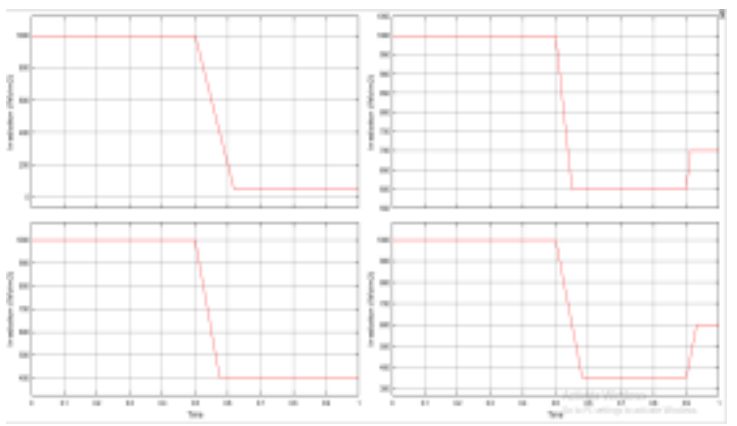

Fig. 8 Varying irradiation input to the solar panels

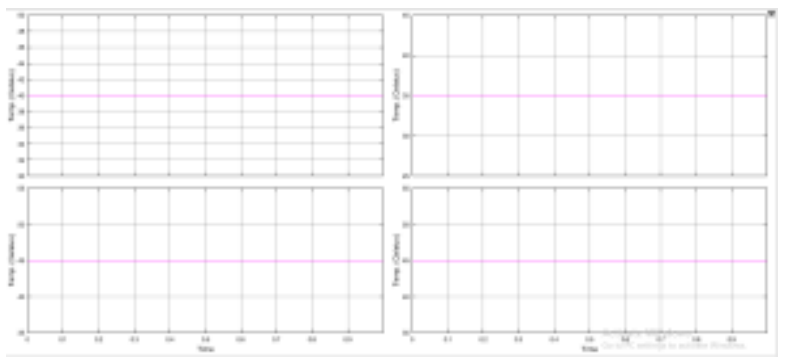

Fig. 9 Varying temperature input to the solar panels

CASE 1: DG with multilevel converter per phase having variable irradiation and basic regulatory PWM control In this case a distributed generation system comprising of solar panels has been developed in MATLAB/SIMULINK. These panels are subjected to variable irradiation and varying temperature. The output from the tem is then analyzed for the changes due their input variation. The output DC voltage is converted in to AC by inverter. This inverter is provided pulses with basic controlling technique by utilizing PWM generator and producing pulses for their regulation. The output is then sent to the transformer after which it is integrated with the grid. The loads are connected at the $10 \mathrm{KV}$ high voltage line.
The graphical output waveforms of voltage, current, active power and reactive power are shown in the figures below. Various loads are also driven to study the system efficiency and reliability.

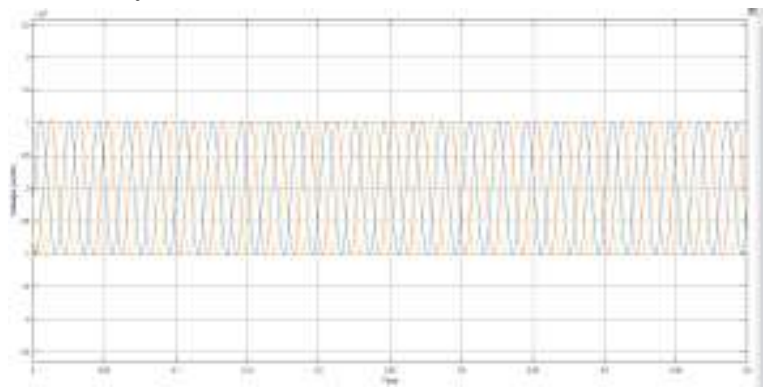

Fig. 10 Voltage in the system with multilevel converter per phase basic regulatory PWM control

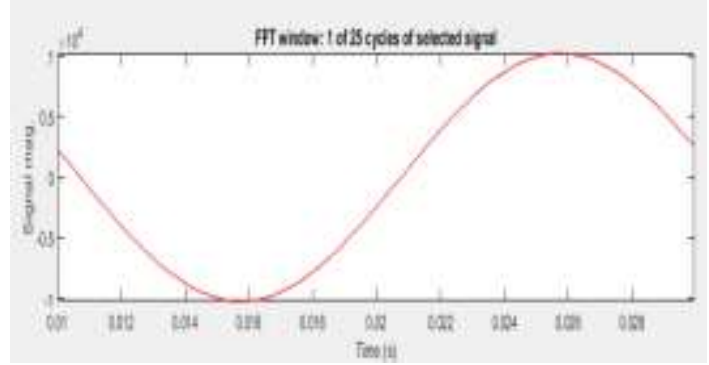

Fig. 11 FFT analysis of voltage output with PWM control of per phase converter

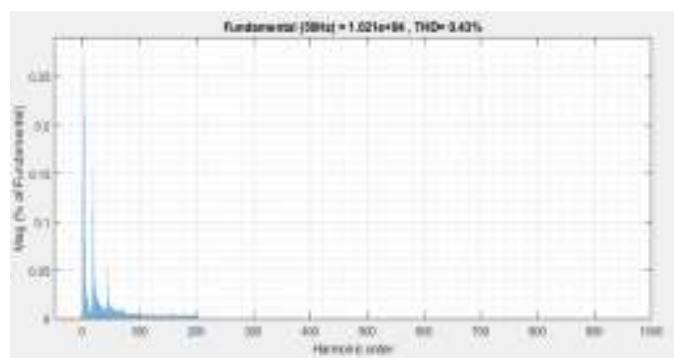

Fig. 12 THD\% of voltage output with PWM control of per phase converter

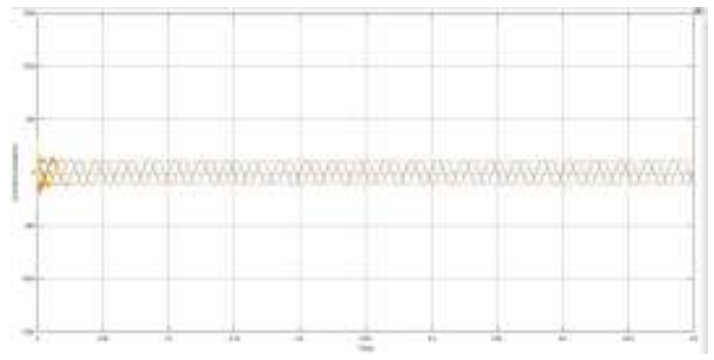

Fig. 13 Current in the system with multilevel converter per phase basic regulatory PWM control

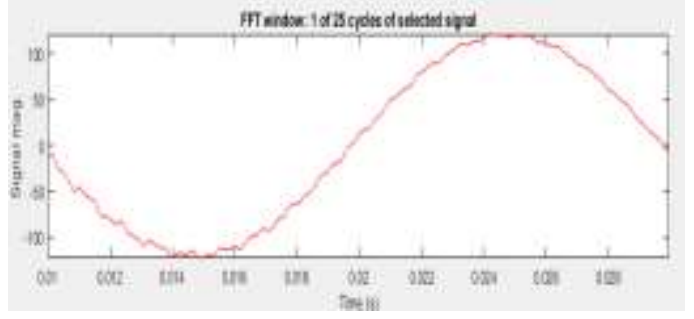

Fig. 14 FFT analysis of current output with PWM control of per phase converter 


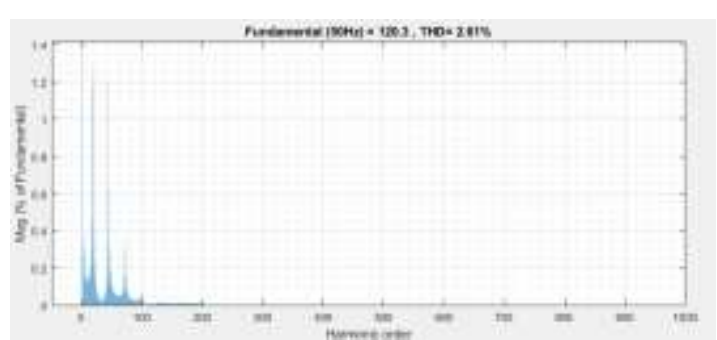

Fig. 15 THD\% of current output with PWM control of per phase converter

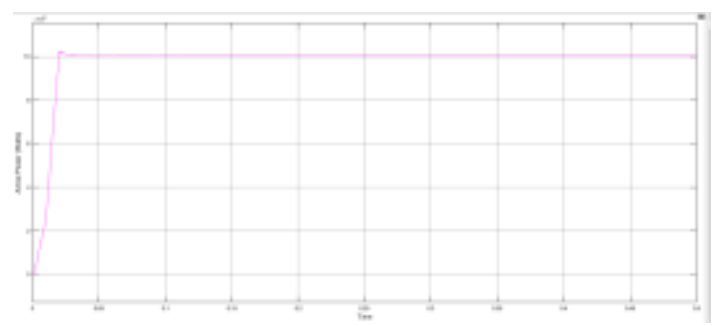

Fig. 16 Active power in the system with multilevel converter per phase basic regulatory $\mathrm{PWM}$ control

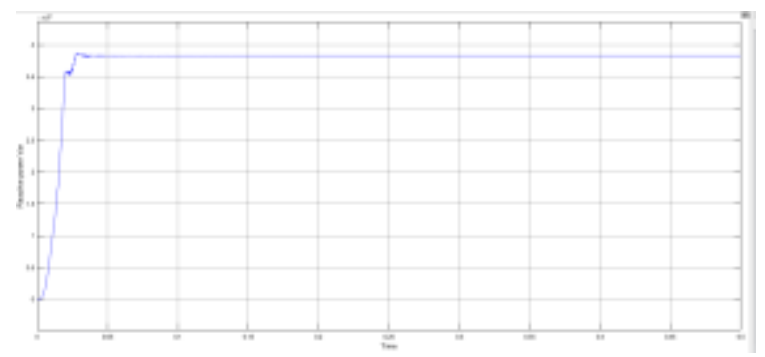

Fig. 17 Reactive power in the system with multilevel converter per phase basic regulatory PWM control

The above waveforms shows the voltage output, current output, active power output, and reactive power in the system having multilevel converter per phase basic regulatory PWM control. It is concluded that the voltage output is coming to be approximately 10 Kilo volts. The current was found o be approximately 120 Ampere with active power output as $1.003 \mathrm{MW}$ and reactive power output as $0.38 \mathrm{MVar}$.

CASE 2: Proposed DG system power regulatory per phase inverter with proposed differential evolutionary pulse regulation control

The converter topology has been supplied pulses utilizing an optimization algorithm. The converter pulses are provided with DC and AC voltage references for optimization through differential evolutionary technique. The converter is made to integrate the solar system to the three phase AC system. There has been designing of per phase inverter and its control while the DGs are fed with different kinds of loads at the high voltage line.

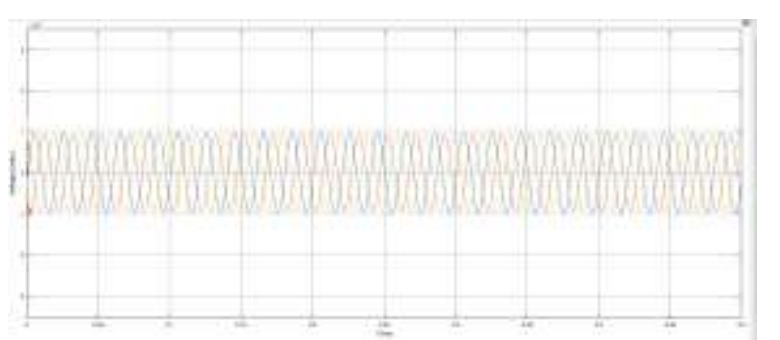

Fig. 18 Voltage in the DG system power regulatory per phase inverter with proposed differential evolutionary pulse regulation control

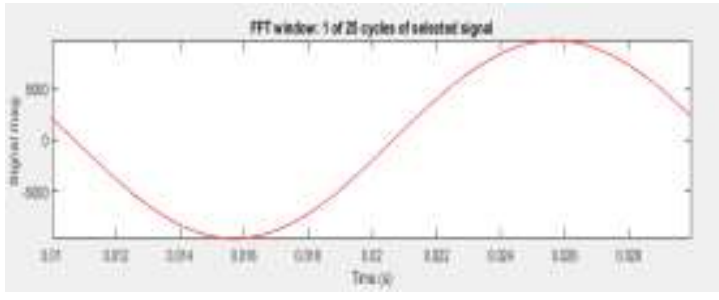

Fig. 19 FFT analysis of voltage output with proposed controller

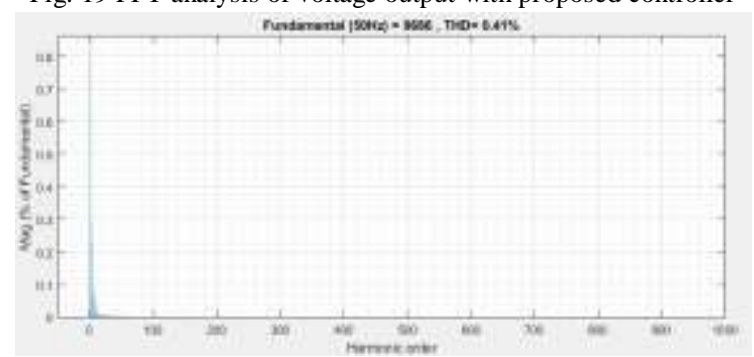

Fig. 20 THD\% of voltage output with proposed controller

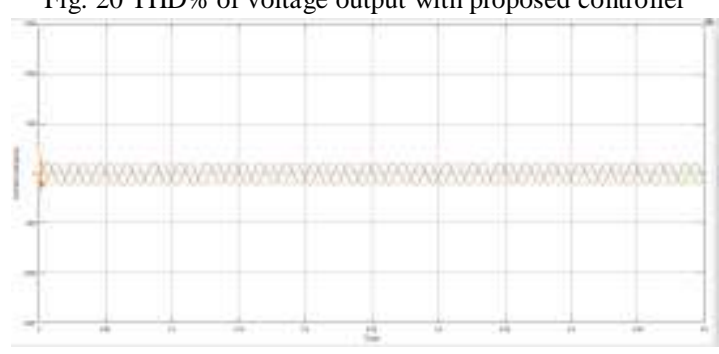

Fig. 21 Current in the DG system power regulatory per phase inverter with proposed differential evolutionary pulse regulation control

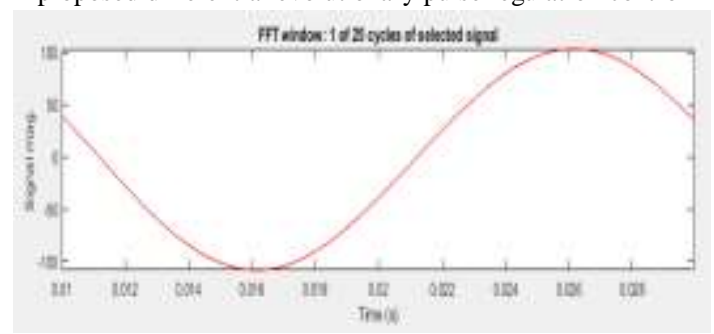

Fig. 22 FFT analysis of current output with proposed controller

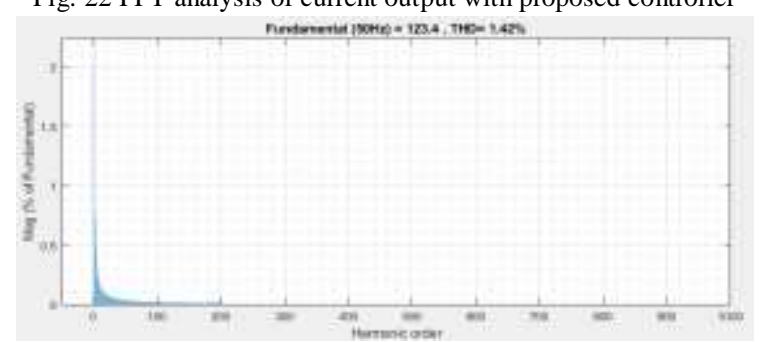

Fig. 23 THD\% of current output with proposed controller 


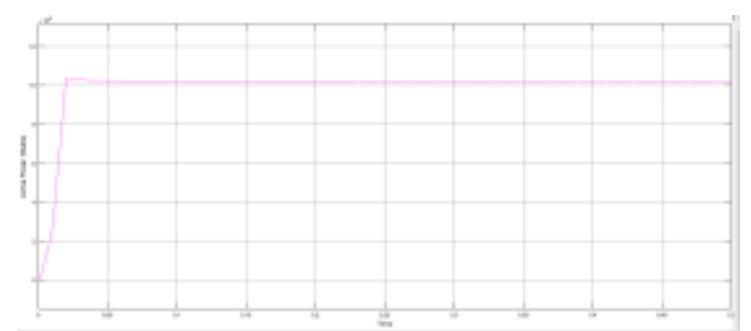

Fig. 24 Active Power in the DG system power regulatory per phase inverter with proposed differential evolutionary pulse regulation control

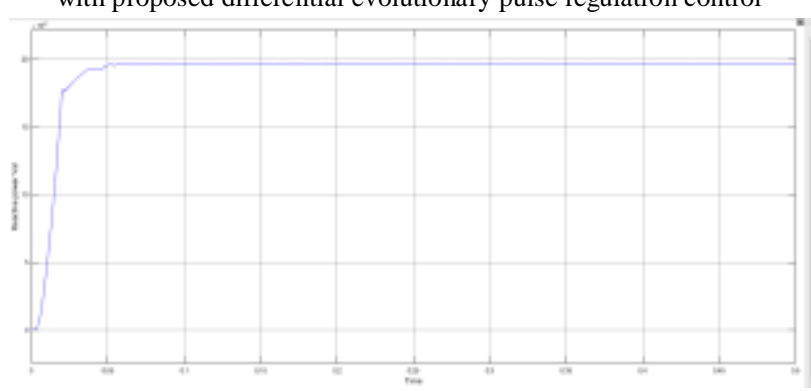

Fig. 25 Reactive Power in the DG system power regulatory per phase inverter with proposed differential evolutionary pulse regulation control In the system having proposed DG system power regulatory per phase inverter with proposed differential evolutionary pulse regulation control the voltage output was found to be approximately 10 Kilo volts. The current was found o be approximately 123 Ampere with active power output as $1.022 \mathrm{MW}$ and reactive power output as $0.196 \mathrm{MVar}$.

Validation

\begin{tabular}{|l|c|c|}
\hline Parameters & $\begin{array}{l}\text { DG solar system with } \\
\text { multilevel converter per } \\
\text { phase basic regulatory } \\
\text { PWM control }\end{array}$ & $\begin{array}{l}\text { DG solar system } \\
\text { having proposed } \\
\text { differential } \\
\text { evolutionary power } \\
\text { pulse regulation } \\
\text { control }\end{array}$ \\
\hline Voltage & $10 \mathrm{KV}$ & $10 \mathrm{KV}$ \\
\hline Current & 120 & 123 \\
\hline $\begin{array}{l}\text { Active } \\
\text { Power }\end{array}$ & $0.43 \%$ & $1.022 \mathrm{MW}$ \\
\hline $\begin{array}{l}\text { THD } \% \text { in } \\
\text { voltage }\end{array}$ & $2.61 \%$ & $0.41 \%$ \\
\hline $\begin{array}{l}\text { THD\% in } \\
\text { current }\end{array}$ & $0.38 \mathrm{MVar}$ & $1.42 \%$ \\
\hline $\begin{array}{l}\text { Reactive } \\
\text { Power }\end{array}$ & \multicolumn{2}{|l}{} \\
\hline
\end{tabular}

It was found that active power output was considered to be enhanced from power of approximately $1.003 \mathrm{MW}$ to 1.022 MW and the voltage was kept constant to $10 \mathrm{KV}$. The objective was to keep the active power output stable and balanced which was obtained from the proposed controller having inverter with differential evolutionary pulse regulation control for each phase of the system. The reactive power was seen to be reduced depicting that the converter in meant for reactive power stabilization/compensation as well with the designed controller.

System analysis with different loads

1 Balanced Three Phase Load:

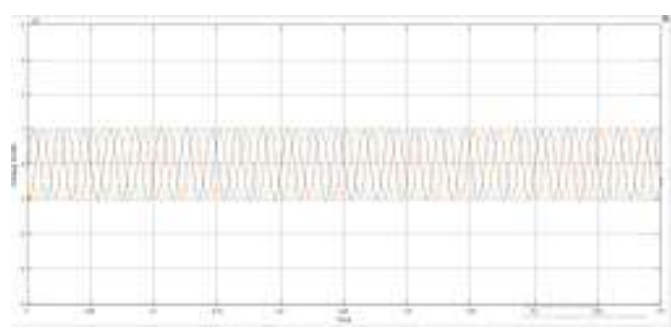

Fig. 26 Voltage at the balanced load terminal

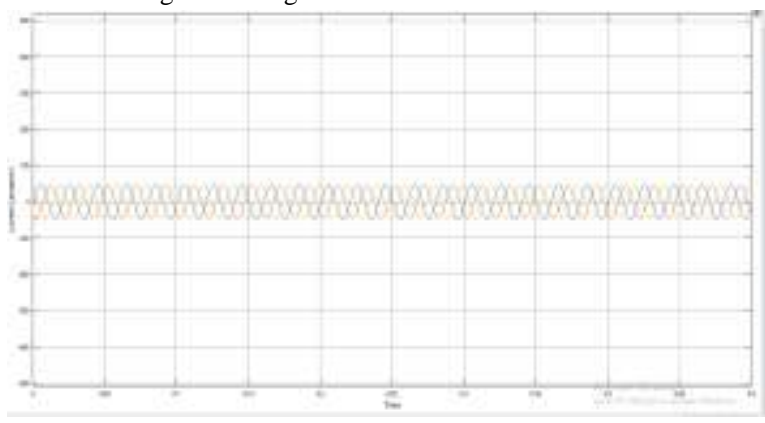

Fig. 27 Current to the balanced Load

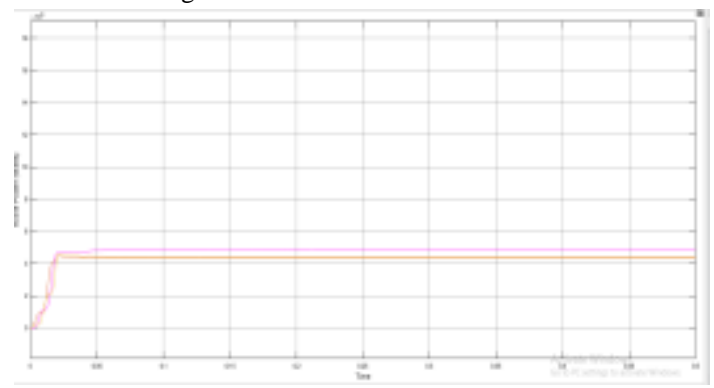

Fig. 28 Active Power at the balanced Load terminal

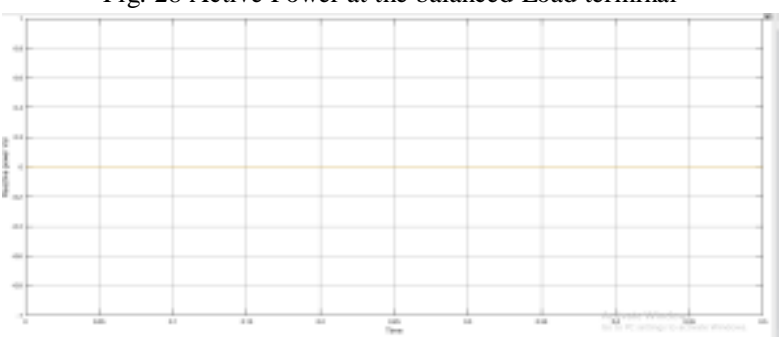

Fig. 29 Reactive Power at the balanced Load terminal

The proposed power regulatory per phase inverter with proposed differential evolutionary pulse regulation control based DG system was made to drive the balanced load of approximately $0.5 \mathrm{MW}$. The power to the load was studied to be stable with sable voltage at the terminal having $10 \mathrm{KV}$ value.

2 Unbalanced Three Phase Load:

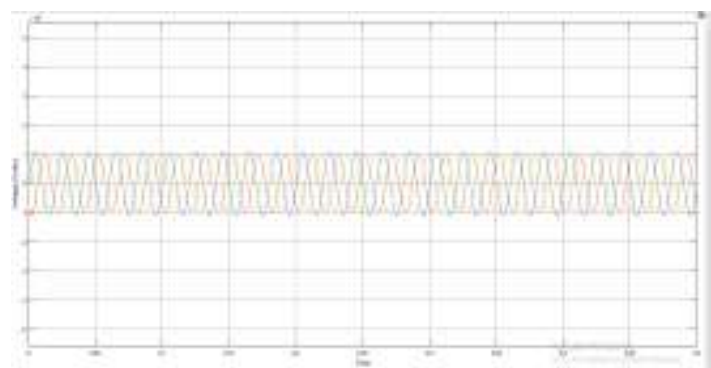

Fig. 30 Voltage at the unbalanced Load 


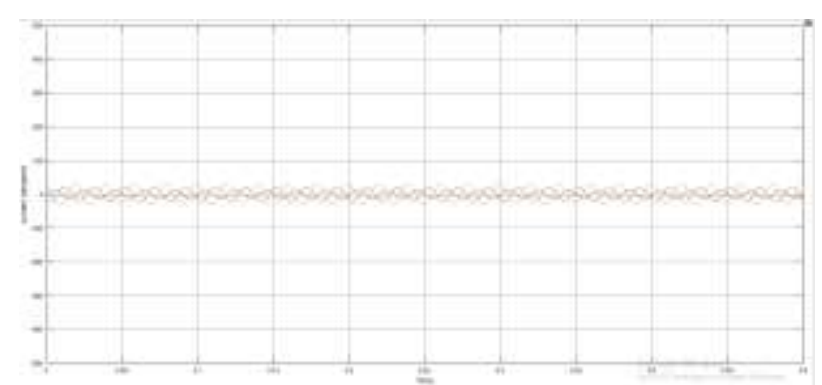

Fig. 31 Current to the unbalanced Load

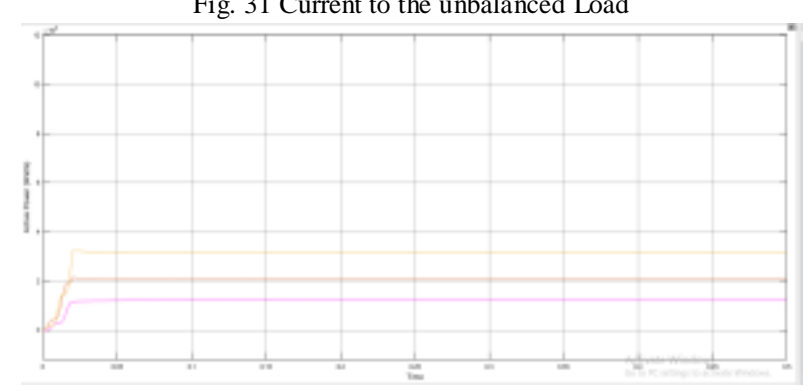

Fig. 32 Active power at the unbalanced Load terminal

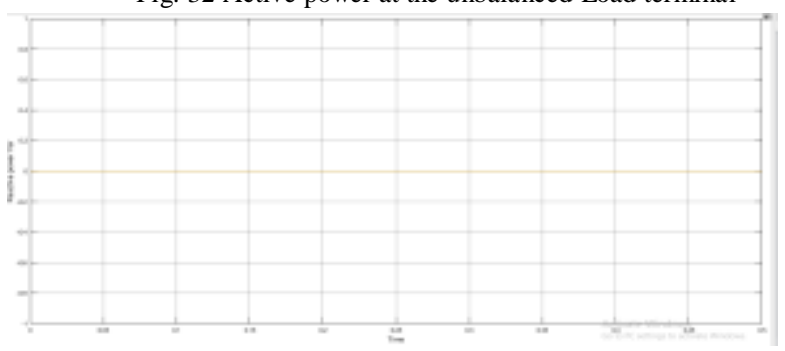

Fig. 33 Reactive power at the unbalanced Load terminal

The per phase loading in this condition is different. It was found that the power at each phase is stable and the voltage at the loading point is maintained to $10 \mathrm{KV}$. The current at each phase is different due to different values of resistive loads.

3 Transient Load Switching

To study the system performance towards changing load conditions at the loading point the various loads in MW are made to switch at different intervals. The system with the proposed differential evolution for power stabilization is studied for its response as the heavy loads are switched into and out from the load line.

During this time the system is expected to maintain the standard voltage at its terminal without any spikes in them and only the current values changes to fulfill the loading conditions.

Initially the system is subjected to drive only the $\mathrm{R}$ load. The $\mathrm{RL}$ load is switched in at 0.1 seconds of the simulation time and is removed at 0.3 seconds. At 0.2 seconds the $\mathrm{RC}$ load is switched into the load line and is removed at 0.3 seconds. After 0.3 Seconds the system resumes its normal operating conditions. The active power changes were smooth and hence the propose DG system with power regulatory per phase inverter with proposed differential evolutionary pulse regulation control is effective in handling load changes. The reactive power also stabilizers in a milliseconds to constant value.

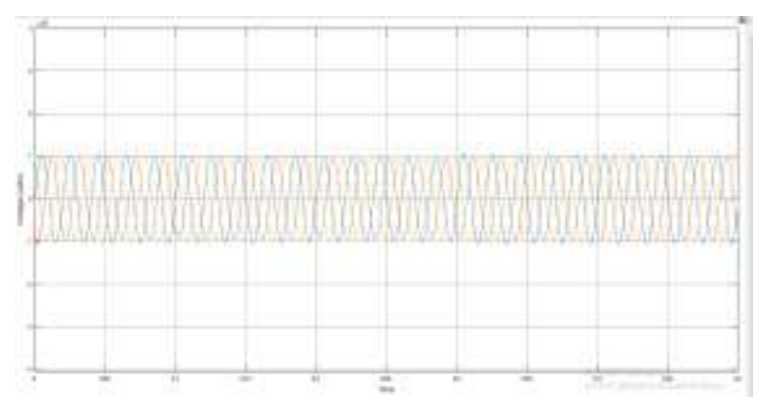

Fig. 34 Voltage in the load line during entire switching times

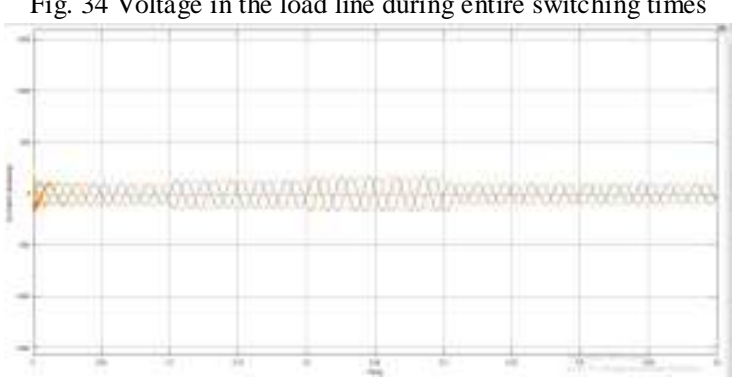

Fig. 35 Current in the load line during entire switching times

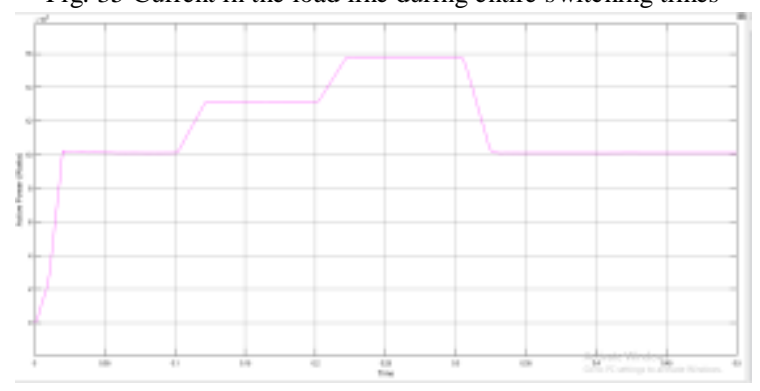

Fig. 36 Active power changes in the load line during entire switching times

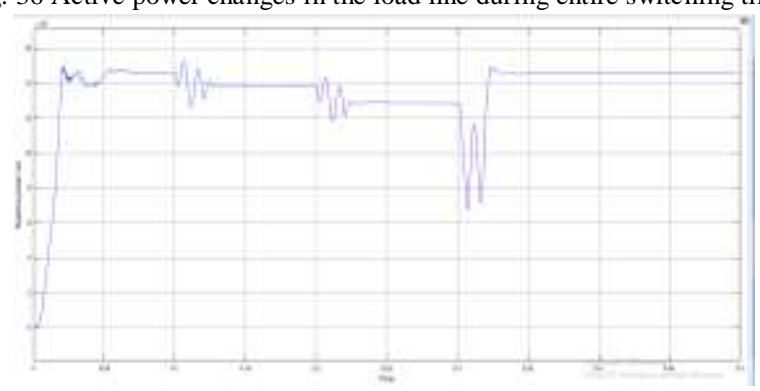

Fig. 37 Reactive power changes in the load line during entire switching times

\section{CONCLUSION}

For on-grid solar power systems, the building is fed from both local grid and a PV array in order to cover the consumer's own power demand and decrease electricity bills. The PV panels are connected with a grid tie inverter that directly converts DC power into AC power. For micro inverters, each PV panel has its own small size inverter, which achieves optimal power conversion for each PV panel. For these inverters, if any PV panel is shaded or is not completely pointed to the sun, the total DC power is not highly affected.

This work provides a comprehensive design and implementation of power regulatory per phase inverter with proposed differential evolutionary pulse regulation control. The Inverter has been provided with proposed optimization technique while integrating it with the grid. 
- The voltage output of the system from the modeled solar system with varying irradiation and temperature control is being fed to the inverter for DC to AC conversion. This voltage is then fed to the grid. The grid voltage being maintained constant to $10 \mathrm{KV}$ in both the systems

- The system designed with this as seen considerable improvement in active power output from the system from approximately $1.003 \mathrm{MW}$ in conventional inverter to $1.022 \mathrm{MW}$ in the proposed scheme.

- The proposed system is also made to feed unbalanced load for the deferent phases to measure its capability of driving various loads.

- Also the value of the reactive power in system having proposed controller is better as compared to value of reactive power in system having basic voltage current regulation in magnitude as well as in stability

- The THD\% in both voltage and current waveforms have been reduced while using power regulatory per phase inverter with proposed differential evolutionary pulse regulation control

- Finally the work is made efficient y integrating it with grid. The designed system is also capable of feeding reactive power to the grid when required.

The computational methodology of the proposed modulation technique is very easy and the technique can be applied to multilevel inverter with any number of levels.

\section{FUTURE SCOPE}

The proposed controller was seen to efficiently balance the active as well as reactive power using the optimization control during the load switching conditions. However the stabilization time of reactive power was more as compared to active power. The controller can be in future modeled for the stabilization time reduction in reactive power as well.

By connecting the super capacitor to the link of an inverter the converter can be designed for a higher voltage and a topology with transformer has to be used. Also the inverter control can be improved employing certain changes in the SPVM such that it can handle balanced and unbalanced DC voltages

The work can further be extended to the hybrid system such that the controller is redesigned to accommodate for changes in both solar input and wind energy system input. The controller has to adjust changes in variation in wind speed as well.

\section{REFERENCES}

[1] Liming Liu, Hui Li "Reactive Power Compensation and Optimization Strategy for Grid-Interactive Cascaded Photovoltaic Systems" Citation information: DOI 10.1109/TPEL.2014.2333004, IEEE Transactions on
Power Electronics, 2014.

[2] Tetali Swathi, V S N Narasimha Raju, K Sainadh Singh, G.Srinivas Reddy, "Design of Cascaded Modular Multilevel Converter for Grid Connected PV System" SSRG International Journal of Electrical and Electronics Engineering 6.4 (2019): 13-21.

[3] Hee-Jun Kim "Special sample and hold techniques", National Semiconductor, Application Report 294. Available: http://www.national.com/an/AN/AN294.pdf

[4] Seyed mahmoudian, M.; Rahmani, R.; Mekhilef, S.; Maung ThanOo, A.; Stojcevski, A.; Soon, TeyKok; Ghandhari, A. S. (2015-07-01). "Simulation and Hardware Implementation of New Maximum Power Point Tracking Technique for Partially Shaded PV System Using Hybrid DEPSO Method". IEEE Transactions on Sustainable Energy. 6 (3): 850862. doi:10.1109/TSTE.2015.2413359. ISSN 1949-3029.

[5] Sonali Surawdhaniwar, Diwan, Ritesh (July 2012). "Study of Maximum Power Point Tracking Using Perturb and Observe Method". International Journal of Advanced Research in Computer Engineering \& Technology. 1 (5): 106-110.

[6] S. Thirumaliah, A.P.Yadav and G. Harith. "Comparison of MPPT Algorithms for DC-DC Converters Based PV Systems" International Journal of Advanced Research in Electrical, Electronics and Instrumentation Engineering Vol. 1, Issue 1, July 2012.

[7] Y.-H.Chang and C.-Y. Chang, "A Maximum Power Point Tracking of PV System by Scaling Fuzzy Control," presented at International Multi Conference of Engineers and Computer Scientists, Hong Kong, 2010.

[8] Zainuri, Pooja Singh, Radzi, M.A.M., Soh, A.C., et al.: 'Development of adaptive perturb and observe-fuzzy control maximum power point tracking for photovoltaic boost dc-dc converter', IET Renew. Power Gener., 2014, 8, (2), pp. 183-194

[9] W. Swiegers, J.H.R. Enslin, M.S. Wolf, D.B. Snyman "Integrated photovoltaic maximum power point tracking converter", IEEE Transactions on Industrial Electronics, vol 44, pp. 769-773, December 1997.

[10] R. Faranda, S. Leva, V. Maugeri, "MPPT techniques for pv systems: energetic and cost comparison.” Proceedings of IEEE Power and Energy Society General Meeting- Conversion and Delivery of Electrical Energy in the 21st Century, 2008, pp. 1-6. 